\title{
Analisis Pengaruh Variasi Temperatur dan Waktu Tahan Tempering Terhadap Kekerasan Material Chain Shackle yang di Hardening Sebagai Solusi Kegagalan Pada Chain Shackle
}

\author{
Redy Rizky Santoso, Rochman Rochiem, dan Wikan Jatimurti \\ Departemen Teknik Material dan Metalurgi FTI-ITS, Kampus ITS-Keputih Sukolilo \\ e-mail:Rochman@mat-eng.its.ac.id
}

\begin{abstract}
Abstrak-Bucket elevator merupakan sebuah komponen yang berfungsi untuk mengakut material yang belum terbentuk menjadi semen. dalam penggunaannya, bucket elevator di hubungkan dengan chain shackle. Chain shackle pada bucket elevator telah mengalami masalah keausan karena material tersebut tidak sesuai dengan standar DIN 745 sehingga diperlukan optimalisasi dengan perlakuan panas. Dalam penelitian ini dilakukan proses analisis pengaruh variasi temperatur dan waktu tahan tempering terhadap kekerasan material chain shackle yang di hardening sebagai solusi kegagalan pada chain shackle. Pengujian yang dilakukan meliputi uji komposisi, metalografi, hardness dan ketahanan aus. Dari hasil uji komposisi didapatkan bahwa material chain shackle adalah baja AISI 1030. kemudian diberi pelakuan hardening-tempering dengan temperatur austenisasi $850^{\circ} \mathrm{C}$ dan dilakukan pendinginan dengan air. Spesimen kemudian ditemper dengan temperatur $200{ }^{\circ} \mathrm{C}, 250{ }^{\circ} \mathrm{C}$, dan $300{ }^{\circ} \mathrm{C}$ dengan waktu tahan tempering 1 jam dan 2 jam. Kekerasan tertinggi terdapat pada spesimen dengan perlakuan tempering $200{ }^{\circ} \mathrm{C}$ dan waktu tahan 1 jam sebesar 588 HV dengan laju keausan 2mm/jam. Berdasarkan hasil pengujian didapatkan bahwa kekerasan berbanding terbalik dengan laju keausan
\end{abstract}

Kata kunci-Bucket Elevator, Chain Shackle, Heat Treatment, kekerasan, ketahanan aus.

\section{PENDAHULUAN}

PT SEMEN Indonesia merupakan produsen semen terbesar di Indonesia. Keberhasilan pembangunan pabrik Tuban IV dan Tonasa V, serta akuisisi perusahaan semen Vietnam Thang Long Cement Company pada akhir tahun 2013, maka pada awal tahun 2013 perseroan memiliki kapasitas terpasang sebesar 30 ton/tahun dan telah menjadi perusahaan semen terbesar di Asia Tengggara berdasarkan kapasitas terpasang. Saat 2014 kapasitas terpasang Semen Indonesia meningkat menjadi 33 juta ton semen per tahun, dan menguasai sekitar $42 \%$ pangsa pasar semen domestik. PT. Semen Indonesia memiliki 4 anak perusahaan yaitu PT. Semen Gresik, PT. Semen Padang, PT. Semen Tonasa, dan Thang Long Cement. Untuk PT. Semen Indonesia sendiri memiliki 4 pabrik dengan kapasitas terpasang 8,5 juta ton semen per tahun yang berlokasi di Desa Sumberarum, Kec. Kerek, Tuban, Jawa Timur.

Pabrik Semen Memiliki beberapa plant salah satunya adalah finish mill. Finish mill merupakan plant yang berfungsi untuk melakukan finishing terhadp semen yang telah dicampur. Sebagian besar komponen dari plant finish mill terdiri dari belt conveyor dan ball mill. Pada penelitian kali ini, plant finish mill yang mengalami masalah adalah finish mill 9 yang baru mulai beroperasi sejak pertengahan 2013. Finish mill 9 yang selanjutnya biasa disebut $\mathrm{OK}$ mill memiliki problem pada bagian bucket elevator. Bucket elevator sendiri berfungsi untuk mengangkat semen yang belum tercampur atau belum memiliki kehalusan yang sesuai. Salah satu bagian bucket elevator yaitu chain shackle yang menempel dengan bucket tersebut. Chain shackle mengalami kegagalan pada tanggal 1 September 2017 berupa keausan pada bagian yang bersinggungan dengan rantai.

Chain shackle tersebut telah diuji komposisi menggunakan Optical Emission Spectroscopy (OES) dan memiliki komposisi yang tidak sesuai dengan standar material chain shackle sehingga diperlukan optimalisasi menggunakan perlakuan panas. Oleh karena itu, penelitian ini bertujuan untuk meningkatkan kekerasan dari chain shackle sehingga kegagalan dapat diminimalisir.

\section{METODOLOGI PENELITIAN}

Hal pertama yang dilakukan adalah me-review dokumen perusahaan untuk mendapatkan data terkait desain, data operasi dan spesifikasi. Kemudian dilakukan preparasi spesimen. Tahap Persiapan ini diperlukan sebelum melakukan pengujian untuk menentukan penyebab kegagalan/keausan Chain shackles pada PT Semen Indonesia. Persiapan ini berupa proses cutting dan sectioning. Proses pemotongan dilakukan pada bagian tengah dan ujung pada Chain shackles yang terindikasi adanya beban siklik dan bagian yang jauh dari aus. Spesimen yang terindikasi adanya beban siklik serta bagian yang jauh dari aus akan diuji sebagai perbandingan antara material yang baru dengan material yang sudah aus/gagal. Selanjutnya dilakukan uji kekerasan pada bagian 
yang dekat dengan daerah aus dan jauh dari daerah aus untuk mengetahui perbedaan kekerasan dan dilakukan pengujian laju keausan untuk mendukung data kekerasan tersebut. Kemudian dilakukan pengujian komposisi kimia. Pengujian komposisi kimia berfungsi untuk mengetahui komposisi kimia yang terdapat pada komponen yang mengalami kegagalan. Pada identifikasi komposisi kimia menggunakan alat optical emission spectroscopy di Politeknik Perkapalan Negeri Surabaya untuk mengetahui komposisi dari chain shackle. Lalu pengamatan metalografi dilakukan untuk mengetahui struktur mikro pada material chain shackle. Preparasi pengujian metalografi meliputi proses pengamplasan dengan amplas grade 80 hingga grade 2000, kemudian dilakukan proses polishing. Etsa yang digunakan adalah etsa nital $4 \%$ dengan perbesaran mikroskop 1000x. setelah mengetahui data awal spesimen, dilakukan proses perlakuan panas sesuai dengan berbagai parameter seperti yang ditunjukan pada gambar 1

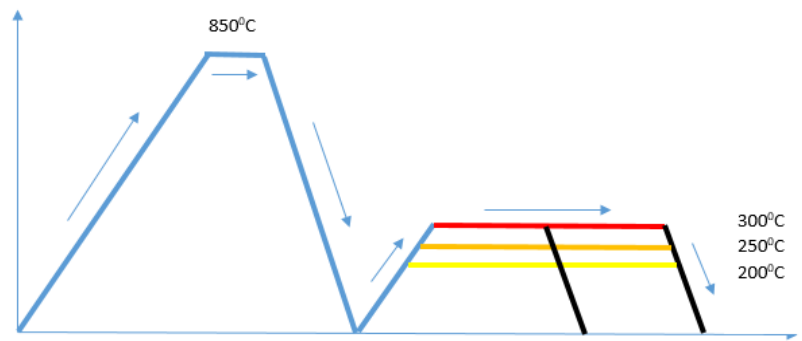

Gambar 1. Kurva Perlakuan Panas Spesimen

Berdasarkan gambar 1, Proses perlakuan panas yang telah dilakukan adalah proses hardening dengan temperatur $850^{\circ} \mathrm{C}$ dan waktu tahan 30 menit. Setelah melakukan proses hardening, spesimen telah diberi perlakuan tempering dengan dua variabel waktu tahan yang berbeda yaitu 60 dan 120 menit. Masing - masing variabel waktu tahan yang berbeda akan di tempering dengan tiga variabel temperatur yang berbeda yaitu $200^{\circ} \mathrm{C}, 250^{\circ} \mathrm{C}, 300^{\circ} \mathrm{C}$. kemudian dilakukan pengujian kekerasan, keausan dan metalografi untuk mengetahui dan membandingkan pengaruh variasi tersebut.

\section{HASIL DAN PEMBAHASAN}

\section{A. Pengujian komposisi}

Material yang digunakan untuk penelitian mempunyai komposisi kimia seperti pada tabel 1 .

Tabel 1.

Komposisi Kimia Material Chain shackle yang Dibandingkan dengan ASTM

\begin{tabular}{cccc}
\hline \hline Unsur & Kadar $(\%)$ & $1030($ ASTM A29) & ASTM A291 \\
\hline $\mathrm{C}$ & 0,299 & $0,28-0,34$ & $0,55 \max$ \\
$\mathrm{Si}$ & 0,245 & - & $0,35 \max$ \\
$\mathrm{Mn}$ & 0,745 & $0,60-0,90$ & $0,60-0,90$ \\
$\mathrm{P}$ & 0,019 & $0,040 \mathrm{max}$ & $0,040 \max$ \\
$\mathrm{S}$ & 0,018 & $0,050 \max$ & $0,040 \max$ \\
$\mathrm{Cr}$ & 0,235 & - & $0,25 \max$ \\
$\mathrm{Mo}$ & 0,014 & - & $0,10 \max$ \\
$\mathrm{Cu}$ & 0,044 & - & $0,35 \max$ \\
\hline \hline
\end{tabular}

\begin{tabular}{cccc}
\hline \hline $\mathrm{Ni}$ & 0,115 & - & $0,30 \max$ \\
$\mathrm{Fe}$ & 98,20 & - & - \\
\hline \hline
\end{tabular}

Tabel 1 merupakan komposisi kimia material chain shackle. Jika dilihat dari komposisinya material tersebut termasuk baja karbon menengah yaitu AISI 1030 [1].

\section{B. Pengamatan Makro}

Berdasarkan hasil pengamatan visual dengan kamera secara makro pada daerah chain shackle yang telah mengalami keausan. Terlihat pada gambar 2 telah terjadi keausan pada bagian chain shackle telah terjadi pengurangan dimensi dengan tebal mula-mula sebesar $37 \mathrm{~mm}$ dan tebal akhir sebesar $19 \mathrm{~mm}$ sehingga terjadi pengurangan $18 \mathrm{~mm}$ pada bagian kanan material chain shackle. Untuk bagian kiri, tebal mula-mula sebesar $37 \mathrm{~mm}$ dan setelah mengalami keausan memiliki tebal akhir sebesar $23 \mathrm{~mm}$ karena telah kehilangan $14 \mathrm{~mm}$ selama proses pengausan terjadi. Berdasarkan pengamatan visual, masih belum terjadi crack pada material chain shackle tersebut.

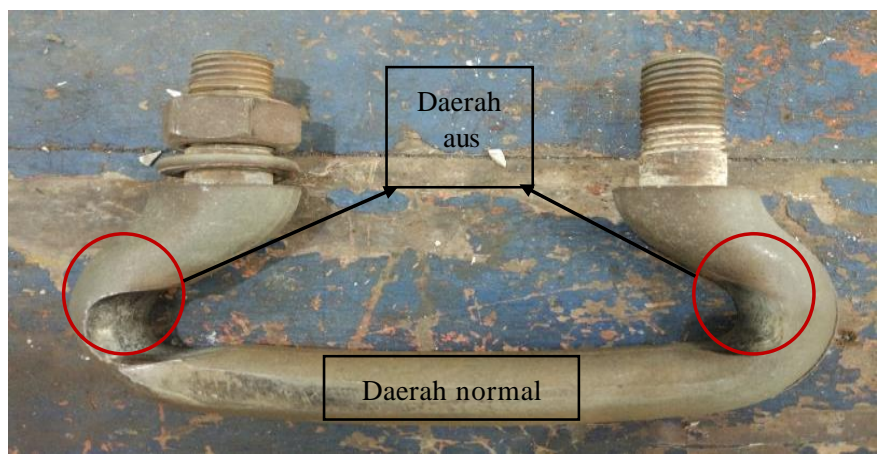

Gambar 2. Hasil Pengamatan Makro Chain Shackle

\section{Pengujian Kekerasan}

Berdasarkan pengujian kekerasan, material chain shackle memeiliki kekeras an seperti pada tabel 2 .

Tabel 2.

Hasil pengujian kekerasan Material Chain shackle yang gagal

\begin{tabular}{ccc}
\hline \hline \multirow{2}{*}{$\begin{array}{c}\text { Titik } \\
\text { indentasi }\end{array}$} & \multicolumn{2}{c}{ kekerasan (HV) } \\
\cline { 2 - 3 } & $\begin{array}{c}\text { Daerah jauh dari } \\
\text { keausan }\end{array}$ & $\begin{array}{c}\text { Daerah dekat } \\
\text { dengan keausan }\end{array}$ \\
\hline 1 & 267 & 278 \\
2 & 271 & 276 \\
3 & 253 & 269 \\
4 & 260 & 272 \\
5 & 275 & 270 \\
Rata-rata & 265.2 & 273 \\
\hline \hline
\end{tabular}

Sedangkan pengujian kekerasan untuk material yang telah diberikan pelakuan hardening dan tempering ditunjukan pada tabel 3 . 
Tabel 3.

\begin{tabular}{lccc}
\multicolumn{4}{l}{ Hasil Kekerasan Material Chain shackle setelah tempering } \\
\hline \hline Material & $\begin{array}{c}\text { Temperat } \\
\text { ur } \\
\left({ }^{\circ} \mathrm{C}\right)\end{array}$ & $\begin{array}{c}\text { Waktu } \\
\text { Tahan } \\
(\text { Menit })\end{array}$ & $\begin{array}{c}\text { Kekerasan } \\
(\mathrm{HV})\end{array}$ \\
\hline HT200t60 & 200 & 60 & 588 \\
HT250t60 & 250 & 60 & 565.4 \\
HT300t60 & 300 & 60 & 530.8 \\
HT200t120 & 200 & 120 & 581.4 \\
HT250t120 & 250 & 120 & 536.6 \\
HT300t120 & 300 & 120 & 515.6 \\
Hardening & - & - & 689.6 \\
\hline
\end{tabular}

Dari data tabel 3, kemudian di plot dalam suatu grafik untuk membandingkan kekerasan pada spesimen pada setiap parameter seperti pada gambar 3 .

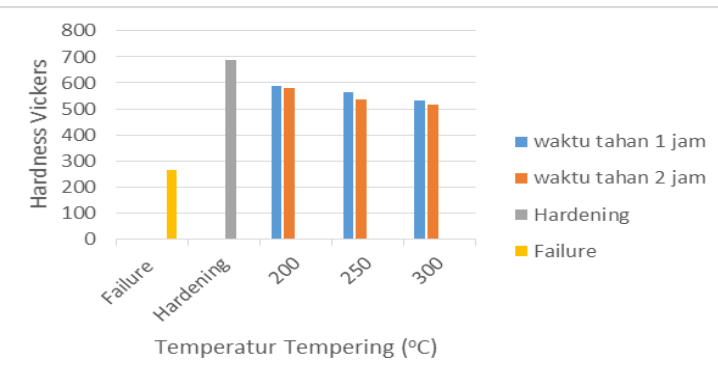

Gambar 3. Perbandingan kekerasan spesimen

\section{Pengamatan Struktur Mikro}

Berdasarkan hasil pengamatan struktur mikro, spesimen pada gambar 4 (a) menunjukan fasa ferrit dan perlit, sedangka struktur mikro chain shackle seharusnya merupakan fasa tempered martensit seperti pada gambar 4 (b).
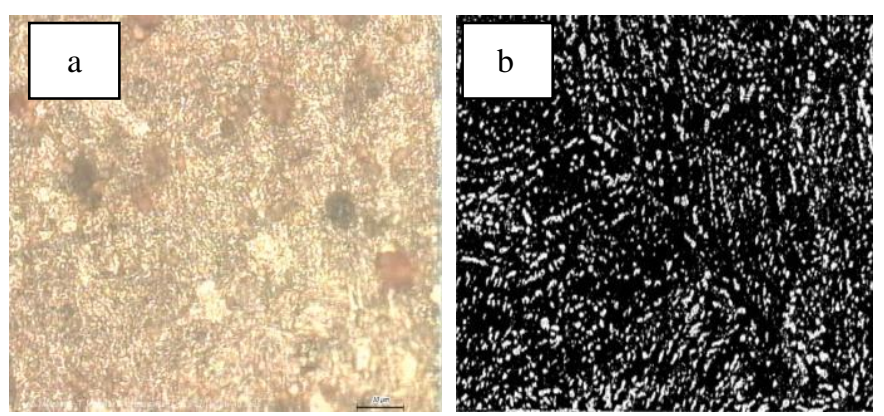

Gambar 4. (a) Hasil Pengamatan Struktur Mikro Menggunakan Etsa Nital 4\% dengan Perbesaran 1000x (b) Struktur Mikro standar chain shackle AISI 1045 Hardening dan Tempering dengan etsa nital 4\% dan perbesaran 3000x

Setelah melalui perlakuan panas hardening dengan temperature austenisasi $850^{\circ} \mathrm{C}$ kemudian didinginkan dengan media air, menghasilkan struktur mikro berupa martensit dan bainit seperti ditunjukan pada gambar 5 .

Kemudian diberikan perlakuan tempering dengan variasi waktu tahan temper dan temperatur temper seperti ditunjukan pada tabel 4 dan menghasilkan strukturmikro seperti pada gambar 6, 7 dan 8

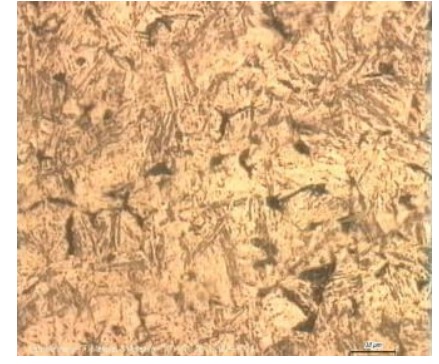

Gambar 5. struktur mikro material chain shackle setelah di-hardening dengan temperature austenisasi $850{ }^{\circ} \mathrm{C}$ dan waktu tahan 30 menit waterquenched dengan etsa nital $4 \%$ dan perbesaran 1000x

Tabel 4.

Tabel Perlakuan Panas

\begin{tabular}{|c|c|c|c|c|c|c|}
\hline Material & $\begin{array}{l}\text { Tem } \\
\text { pera } \\
\text { tur } \\
\left({ }^{\circ} \mathrm{C}\right)\end{array}$ & $\begin{array}{c}\text { Wak } \\
\text { tu } \\
\text { Tah } \\
\text { an } \\
\text { (Me } \\
\text { nit) } \\
\end{array}$ & $\begin{array}{c}\text { Uji } \\
\text { kom } \\
\text { posi } \\
\text { si }\end{array}$ & $\begin{array}{c}\text { Uji } \\
\text { Met } \\
\text { alog } \\
\text { rafi }\end{array}$ & $\begin{array}{c}\text { Uji } \\
\text { Keker } \\
\text { asan }\end{array}$ & $\begin{array}{c}\text { Uji } \\
\text { Keau } \\
\text { san }\end{array}$ \\
\hline $\mathrm{N}$ & - & - & V & V & $\mathrm{V}$ & V \\
\hline HT200t60 & 200 & 60 & - & V & V & $\mathrm{V}$ \\
\hline HT250t60 & 250 & 60 & - & V & V & V \\
\hline HT300t60 & 300 & 60 & - & V & V & $\mathrm{V}$ \\
\hline HT200t 120 & 200 & 120 & - & V & V & V \\
\hline HT250t 120 & 250 & 120 & - & V & $\mathrm{V}$ & V \\
\hline HT300t 120 & 300 & 120 & - & $\mathrm{V}$ & $\mathrm{V}$ & V \\
\hline
\end{tabular}
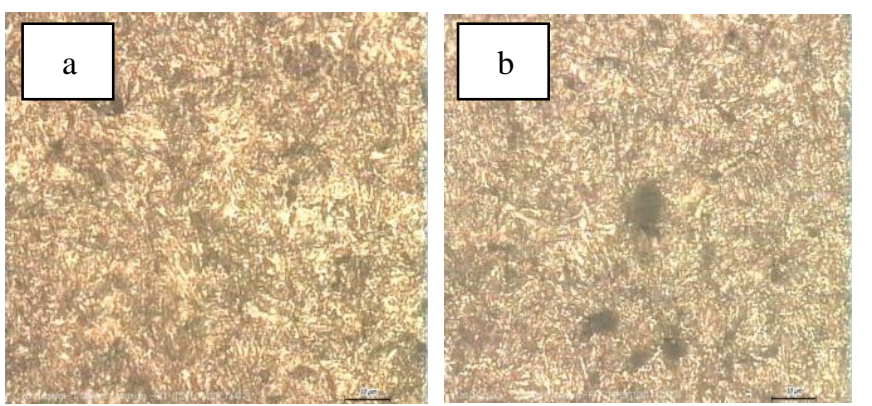

Gambar 6. struktur mikro material chain shackle dengan temperature tempering $200^{\circ} \mathrm{C}$ dan waktu tahan tempering A.1 jam dan B. 2 jam dengan etsa nital $4 \%$ dan perbesaran 1000x

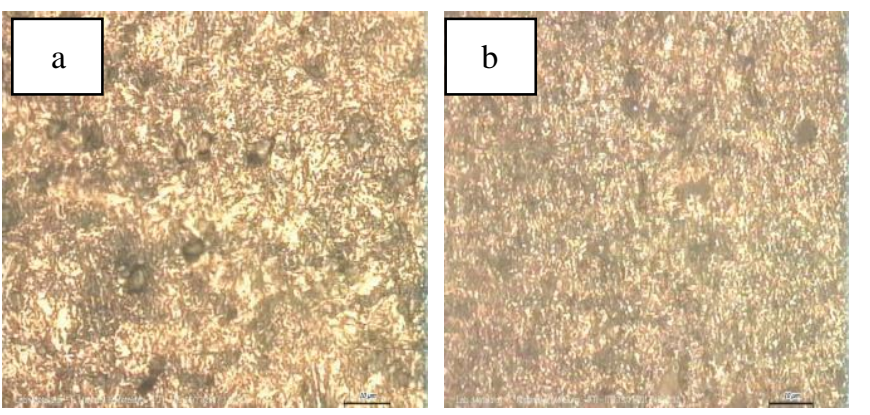

Gambar 7. struktur mikro material chain shackle dengan temperature tempering $250^{\circ} \mathrm{C}$ dan waktu tahan tempering A.1 jam dan B. 2 jam dengan etsa nital $4 \%$ dan perbesaran $1000 \mathrm{x}$ 


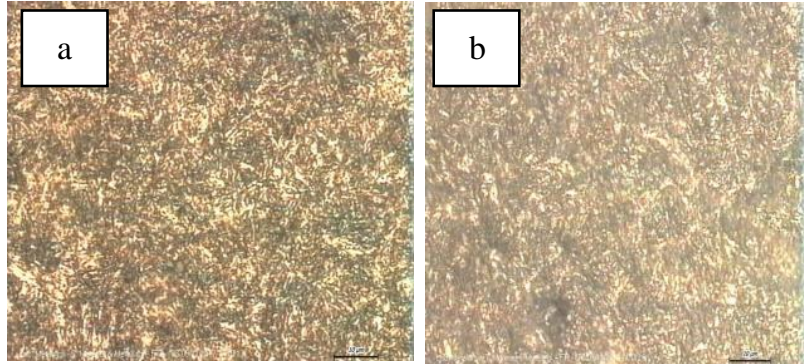

Gambar 8. struktur mikro material chain shackle dengan temperature tempering $300^{\circ} \mathrm{C}$ dan waktu tahan tempering A.1 jam dan B. 2 jam dengan etsa nital $4 \%$ dan perbesaran $1000 \mathrm{x}$

\section{E. Pengujian keausan}

Berdasarkan uji keausan dengan standar [2], didapatkan laju keausan seperti ditunjukan pada tabel 5 .

Tabel 5.

Hasil pengujian keausan

\begin{tabular}{ccc}
\hline \hline Material & $\begin{array}{c}\text { Penguran } \\
\text { gan } \\
\text { ketebalan } \\
(\mathrm{mm})\end{array}$ & $\begin{array}{c}\text { Keausan } \\
(\mathrm{mm}) / \text { waktu(jam) }\end{array}$ \\
\hline HT200t60 & 0.1 & 2 \\
HT250t60 & 0.13 & 2.67 \\
HT300t60 & 0.16 & 3.33 \\
HT200t120 & 0.13 & 2.67 \\
HT250t120 & 0.16 & 3.33 \\
HT300t120 & 0.3 & 4.67 \\
Tanpa & 0.36 & 7.33 \\
Perlakuan & & \\
\hline \hline
\end{tabular}

Kemudian data tersebut diplot dalam sebuah grafik untuk membandingkan laju keausan antar spesimen seperti ditunjukan pada gambar 9 .

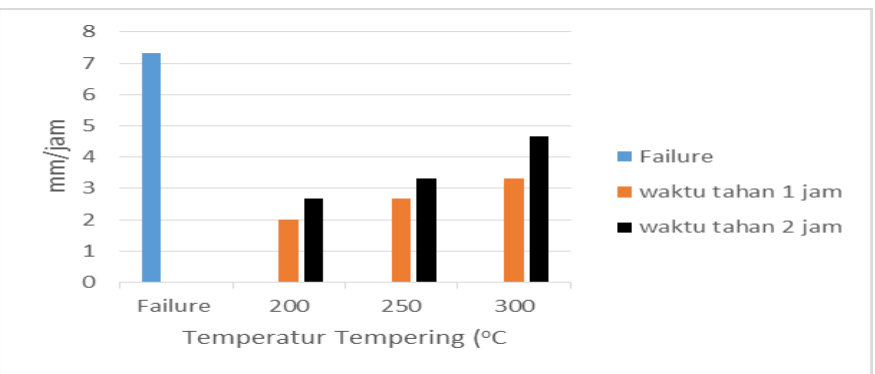

Gambar 9. grafik laju keausan spesimen

\section{F. Pembahasan}

Setelah melakukan beberapa pengujian yang telah dilakukan selama penelitian ini, pada umumnya terdapat beberapa faktor yang menyebabkan kegagalan pada material yaitu kesalahan dalam pemilihan material. Hal tersebut dapat ditinjau berdasarkan komposisi dan kekerasan pada permukaan, serta struktur mikro yang terdapat pada material yang gagal tersebut.

Material standar yang digunakan untuk chain shackle ini adalah baja aisi 1045 dengan komposisi sesuai dengan [1] dan telah diberi perlakuan hardening dan tempering. Sedangkan berdas arkan hasil uji komposisi optical emission spectroscopy (OES). Material yang didapat tidak sesuai dengan standar untuk aplikasi chain shackle. Dari segi kadar karbon, spesimen chain shackle memiliki kadar karbon (C) yang lebih rendah bila dibandingkan dengan standar material chain shackle [3], sehingga dari segi kekerasan masih tidak sesuai dengan standar yang seharusnya $600 \mathrm{HV}$. Selain itu, material chain shackle dari PT. Semen Indonesia Tbk memiliki paduan seperti $\mathrm{Cr}$ dan Mo yang tidak sesuai dengan standar sehingga kemampuan untuk dikeraskannya rendah. Gesekan yang dihasilkan oleh chainlink dan chain shackle membuat material tersebut mengalami keausan hingga hampir kehilangan setengah diameternya dan membuat material tersebut memiliki internal stress yang tinggi. Dari segi chainlink sendiri tidak mengalami masalah keausan sehingga dapat disimpulkan kesalahan pemilihan material berada pada chain shackle. Berdasarkan data fakta diatas, lifetime dari chain shackle harusnya bisa lebih dari empat tahun (asumsi maksimal).

Berdasarkan hasil pengamatan strukturmikro, diketahui bahwa struktur mikro awal material chain shackle yang terbentuk sebelum spesimen tersebut diberikan perlakuan panas menunjukan fasa ferrit dan perlit yang merupakan struktur mikro dari baja hypoeutektoid [4]. Sedangkan seharusnya struktur mikro dari chain shackle sharusnya berupa hasil dari hardening dan tempering yaitu berupa tempered martensite [5]. Tempered martensit menghasilkan material yang keras namun memiliki ketangguhan yang lebih tinggi jika dibandingkan dengan fasa martensit. Dari hasil fasa yang diperoleh pada material chain shackle PT. Semen Indonesia Tbk sangat jauh dari material standar chain shackle.

Setelah diberi perlakuan panas berupa hardening dengan temperature $850^{\circ} \mathrm{C}$ dengan waktu tahan 30 menit dan media pendingin air. Struktur mikro yang diperoleh adalah martensit. Jenis martensit yang terbentuk adalah lath martensit dan bainit bawah. Lath martensit terbentuk pada hardening baja karbon dengan komposisi di bawah 0.6\% [5]. Sedangkan bainit bawah yang merupakan agregat dari ferrite dan cementite (Fe3C) terbentuk pada kecepatan pendinginan sedang dimana pada kondisi ini karbon sulit berdifusi kedalam fasa austenite [6]. Kemudian diberikan perlakuan temper dimana perubahan besar terjadi pada martensit pada saat diberi pelakuan tersebut adalah difusi karbon ke batas butir untuk melepas tegangan sis a dan presipitasi karbida epsilon sebagai dampak dari difusi karbon [7]. Kekerasan spesimen menurun setelah ditemper dikarenakan tempering bertujuan untuk mengembalikan sebagian keuletan/ketangguhan, berakibat turunnya kekerasan, dan melepas tegangan dalam untuk memperoleh keuletan yang lebih baik. [8]. Dengan parameter yang ada, spesimen yang memiliki kekerasan paling tinggi adalah spesimen dengan kode HT200T60. Hal tersebut dikarenakan fasa yang terbentuk berupa tempered martensit dengan ukuran yang lebih besar dan tidak terjadi perubahan pada ferit [9]. Pada spesimen tersebut, karbida epsilon yang terbentuk masih sangat sedikit namun terjadi penurunan kekerasan yang cukup signifikan dibandingkan dengan spesimen yang hanya dilakukan proses hardening water-quenched. Spesimen diatas memiliki kekerasan yang tinggi karena temperature tempering berturutturut rendah dan cepat sehingga dekomposisi martensit masih belum terjadi. Fasa karbida epsilon merupakan senyawa 
submikroskopik sebagai tanda awal tempering dilakukan pada temperature pada kisaran $100-200^{\circ} \mathrm{C}$. Pada temperature ini, senyawa submikroskopik tersebut berupa $\mathrm{Fe}_{2.4} \mathrm{C}$ yang selanjutnya berubah menjadi $\mathrm{Fe}_{3} \mathrm{C}$ ketika temperature dinaikan [10]. Penambahan temperatur dan waktu tahan tempering telah menyebabkan penurunan kekerasan dan kekuatan, namun telah meningkatkan keuletan dan ketangguhan. Dari hasil pengujian, spesimen yang memiliki kekerasan paling rendah yaitu spesimen dengan kode HT300T120 dengan fasa tempered martensit, ferit, dan sedikit perlit. Pada temperature ini terjadi perubahan signifikan pada fasa tempered martensit yaitu pada spesimen ini, martensit yang diperoleh sudah tidak tajam dan tidak kontinyu dan mulai terjadi pembentukan ferrit dan perlit sehingga diperoleh peningkatan keuletan [9] sekaligus menyebabkan terjadinya penurunan kekerasan. Akumulasi karbida epsilon membentuk sementit ketika temperature dinaikan sehingga kekerasan tidak sebanding dengan spesimen HT200T60 [11]. Setiap spesimen tidak menunjukan adanya bentuk dari fasa karbida karena terdapat unsur silicon dalam material chain shackle. Silicon tidak dapat larut dalam sementit pada proses awal tempering sehingga menyebabkan senyawa karbida terbentuk memerlukan waktu yang lebih lama dibandingkan tanpa paduan silicon [12].

Berdasarkan data yang diperoleh dari uji kekerasan setelah spesimen diberikan perlakuan panas berupa harden-temper dengan temperature tempering $200^{\circ} \mathrm{C}, 250^{\circ} \mathrm{C}$ dan $300^{\circ} \mathrm{C}$ dengan waktu tahan tempering satu jam dan dua jam telah diperoleh hasil kekerasan. Spesimen pada daerah yang jauh dari daerah keausan memiliki kekerasan sebesar 265.2 HV. Sedangkan pada daerah yang dekat dengan daerah keausan memiliki kekerasan sebesar 273 HV. Kemudian pada daerah material yang mengalami keausan memiliki kekerasan sebesar $279.2 \mathrm{HV}$. Setelah dilakukan perlakuan panas spesimen dengan kode HT200T60 menghasilkan kekerasan yang paling tinggi yaitu $588 \mathrm{HV}$. Kemudian dilanjutkan dengan spesimen dengan kode HT200T120 dengan kekerasan 581.4 HV. Spesimen dengan kode HT250T60 dan kode HT250T120 memiliki kekerasan berturut-turut sebesar 565.4 HV dan 536.6 HV. Spesimen dengan kekerasan terendah dimiliki oleh kode HT300T60 dengan kekerasan 530.8 HV dan HT300T60 dengan kekerasan $515.6 \mathrm{HV}$. Semua spesimen mengalami penurunan kekerasan setelah dilakukan proses tempering dengan parameter yang berbeda-beda bila dibandingkan dengan spesimen yang mengalami proses hardening saja yaitu memiliki kekerasan 686.6 HV. Hal ini terjadi karena pendinginan non-ekuilibrium atau pendinginan sangat cepat dapat meningkatkan nilai kekerasan suatu material dan kekerasan tertinggi diperoleh pada spesimen yang menggunakan air sebagai media pendinginnya [13]. Sedangkan perlakuan tempering memberikan penurunan kekerasan ketika terjadi kenaikan temperatur tempering karena pembentukan karbida epsilon berfungsi untuk menghindari material dari patah getas [14].

Dari pengujian keausan menunjukan hasil yang berbanding lurus bila dibandingkan dengan hasil dari pengujian kekerasan sehingga dapat disimpulkan bahwa peningkatan kekerasan juga telah meningkatkan hasil ketahanan aus dari material tersebut. Dengan menggunakan mesin pin on disc dan beban yang kostan sebesar $1.8 \mathrm{Kg}$ didapatkan spesimen dengan laju keausan terendah terdapat pada spesimen dengan kode HT200T60 dengan laju keausan 2mm/jam. Spesimen lain dengan kode HT200T120 dan HT250T60 memiliki laju keausan yang sama yaitu $2.67 \mathrm{~mm} / \mathrm{jam}$. Spesimen dengan kode HT250T120 dan HT300T60 memiliki laju keausan yang sama pula yaitu sebesar $3.33 \mathrm{~mm} / \mathrm{jam}$. Sedangkan laju keausan tertinggi dimiliki oleh spesimen dengan kode HT300T120 dengan laju keausan $4.67 \mathrm{~mm} / \mathrm{jam}$. Laju keausan menurun bila dibandingkan dengan spesimen yang tidak diberi pelakuan panas yaitu dengan laju $7.33 \mathrm{~mm} / \mathrm{jam}$. Kekerasan suatu material sangat mempengaruhi tingkat ketahanan aus dari material ters ebut [15]. Pada abrasive wear, kekerasan adalah sifat yang paling penting untuk meningkatkan kemampuan suatu baja terhadap ketahanan aus dikarenakan goresan. Makin keras material tersebut, makin sulit media abrasive untuk melakukan penetrasi dan menggores material tersebut [16]. Pengaruh proses tempering adalah hilangnya sebagian tetragonalitas dari martensit, presipitasi besi karbida dan dekomposisi austenit sisa menjadi ferit dan sementit [17]. Perubahan struktur mikro tersebut membuat laju keausan semakin meningkat setelah mengalami proses tempering

\section{KESIMPULAN}

Berdasarkan pengujian yang telah dilakukan, diperoleh beberapa kesimpulan sebagai berikut:

1. Pengaruh waktu tahan tempering terhadap kekerasan dan struktur mikro adalah semakin lama waktu tahan tempering, maka kekerasan akan menurun dan struktur mikro yang terbentuk adalah tempered martensit dan senyawa karbida

2. Pengaruh temperatur tempering terhadap kekerasan dan struktur mikro adalah semakin tinggi temperatur tempering, maka kekerasan akan menurun dan struktur mikro yang terbentuk adalah tempered martensit dan senyawa karbida

\section{DAFTAR PUSTAKA}

[1] A. A29, Standard Specification for Steel Bars, Carbon and Alloy, Hot-Wrought and ColdFinished. USA: ASM International, 1999.

[2] A. G99, Standard Test Method for Wear testing with Pin-onDisk Apparatus. USA: ASM International, 2003.

[3] D. 745, Chain U-links (shackles) for conveyors. Germany: DIN Standart, 1994.

[4] S. H. Avner, Introduction To Physical Metallurgy. Singapore: Mc Graw Hill, 1974.

[5] Sandvik, "Crystallography and Substructure of Lath Martensite Formed in Carbon Steels," 2003.

[6] Aisyah, "Perubahan Struktur Mikro dan Sifat Mekanik Pada Pengelasan Drum Baja Karbon Wadah Limbah Radioaktif.," Yogyakarta, 2011.

[7] E. . Galindo Nava, A model for the microstructure behaviour and strength evolution in lath martensite. United Kingdom, 2015.

[8] D. Prasetya, “ANALISIS PENGARUH VARIASI WAKTU TAHAN TEMPERING DAN TEMPERATUR TEMPERING 
TERHADAP KEKERASAN MATERIAL CROSSBAR YANG DIHARDENING SEBGAI SOLUSI KEGAGALAN PADA CROSSBAR,” 2017.

[9] Z.-B. Xu, "Mechanical Properties of a microalloyed bainitic steel after hot forging," 2017.

[10] A. A973, Standard Specification for Grade 100 Alloy Steel Chain. USA, 2003.

[11] S. and Screniner, "Tempering of Martensite: A Field Ion Microscope Study," 1971.

[12] C. Maherios, "Mechanical behavior of tempered martensite: Characterization and modeling," 2017.

[13] dan Y. S. Bayu Adie Septianto, "Pengaruh Media Pendingin pada Heat treatment Terhadap Struktur Mikro dan Sifat
Mekanik Friction Wedge AISI 1340," 2013.

[14] Ebrahimi-Zia, "MECHANISMS OF TEMPERED MARTENSITE EMBRITTLEMENT IN MEDIUM-CARBON STEELS," 1984.

[15] I. Isnauri, "ANALISA PENGARUH BEBAN TERHADAP LAJU KEAUSAN AL-Si ALLOY DENGAN METODE PIN ON DISK TEST," 2012.

[16] V. Ratia, "Behavior of Martensitic Wear Resistant Steels in Abrasion and Impact Wear Testing Conditions," 2015.

[17] M. Sadat Hamzah, "PENINGKATAN KETAHANAN AUS BAJA KARBON RENDAH DENGAN METODE CARBURIZING," 2008. 